\title{
Consumer Conformity, Social Ties and EWOM in Digital Marketing
}

\author{
Badawi Badawi ${ }^{1}$, Arif Nurudin ${ }^{2}$, Muafi Muafi ${ }^{3 *}$ \\ ${ }^{1}$ Management Department, Universitas Muhammadiyah Cirebon, West Java 45153, Indonesia \\ ${ }^{2}$ Industrial Engineering Department, Universitas Muhammadiyah Cirebon, West Java 45153, Indonesia \\ ${ }^{3}$ Management Department, Universitas Islam Indonesia, Daerah Istimewa Yogyakarta 55283, Indonesia
}

Corresponding Author Email: muafi@uii.ac.id

https://doi.org/10.18280/isi.260607

Received: 12 October 2021

Accepted: 3 December 2021

\section{Keywords:}

digital marketing, consumer conformity, social ties, EWOM, purchase intention

\begin{abstract}
Digital marketing is a marketing technique that is widely discussed in the latest literature. The complexity of digital marketing creates new variables in an effort to increase purchase intention, such as consumer conformity, social ties and EWOM (Electronic Word of Mouth). This study aims to analyze the relationship between consumer conformity, social ties, and EWOM in digital marketing on the Shopee, Lazada, and Bukalapak platforms. Through quantitative methods using Structural Equation Modeling (SEM) analysis using AMOS software on 200 respondents consisting of users of the Shopee, Lazada, and Bukalapak platforms. This study analyzes 5 hypotheses, which is then statistically proven to have a significance value of $<0.05$, which means that there is a significant relationship between the variables, thus all hypotheses are supported. The results indicate that social ties and EWOM can have a significant effect on consumer conformity and are also able to directly affect purchase intention. This research also highlights that consumer conformity has a significant effect on purchase intention in digital marketing.
\end{abstract}

\section{INTRODUCTION}

The rapid development of digital technology and the occurrence of the COVID-19 pandemic in almost all parts of the world has resulted in people reducing direct social interaction. This gives rise to conditions where social interaction occurs more in cyberspace or virtual worlds than in the real world. Of course, digital interactions through cyberspace have many weaknesses, such as the possibility of miscommunication, dependence on internet network connections, not being able to make physical contact, and the need for more efforts to create trust in communication.

However, many things that are impossible in the real world become possible in cyberspace through digital communication, such as communicating with several people from various regions simultaneously and sending messages to hundreds or even millions of people in just seconds. This condition causes distance and time to no longer be an important problem in interactions in cyberspace and of course a great opportunity in the business world, especially in the concept of marketing.

Even though it has many opportunities, the marketing concept in the digital era has big challenges. The society 5.0 is the smart society which requires more than just one-sided information from the firms to make decisions. In the past, the firms rely on TV commercials and advertising to get people to buy their products. Currently, the competition has shifted to a much higher level where people are not easily persuaded. They seek information from the social media and their social networks, then make decisions after they compromise the choices with their images. The changes that occur in the community require companies to put forward the trust and feedback from consumers, as well as social-based marketing and scarcity strategy in order to gain consumer conformity.
The firms have moved to social commerce, timing coordination, and scarcity strategies to get people conforming to buy their products.

The concept of digital-based marketing is becoming a trend today. The digital world has a big influence on people's lives, including in growing purchase intention of products and services. When a product or service is widely known by most people, it will automatically attract more and more enthusiasts periodically; as this condition is a consumer conformity.

An indirect trend or agreement in society that is followed by other parts of society is called conformity. If the condition is related to the purchase of a product or service, it is called consumer conformity. A number of literatures prove that consumer conformity is an important variable in increasing purchase intention [1-6]. Princes \& Manurung [1] stated that by understanding consumer conformity, companies will be able to predict trends in the future, hence increasing the market share. Princess et al. [2, 5] also emphasized the crucial role of consumer conformity in increasing purchase intention as well as showing the solution that consumer conformity can be strived by companies through social interaction. Khandelwal et al. [4] introduced the concept of e-consumer conformity, in which building the conformity can be done through social media marketing. Therefore, building good relationship with consumers is the main task for companies, and it can be done through maintaining social relationship and social media marketing.

Consumer conformity is a powerful marketing tool that is widely used by large companies. There are several factors that have been proven in the literatures to be able to increase consumer conformity, including social ties [1, 2, 7-9] and EWOM [10-13]. The relationship between consumer conformity, social ties, EWOM, and purchase intention at the 
same time is rarely discussed in the latest literature, especially in the context of digital marketing so that the discussion in this study will provide novelty in digital marketing theory.

\section{LITERATURE REVIEW}

\subsection{Consumer conformity}

Consumer conformity is the tendency of group members to establish a group norm and the tendency of individuals to comply with the respective norm [4]. Consumer conformity is formed from the relationship between social interactions and consumer purchasing decisions for products and services. Consumer conformity is a form of conformity of consumers to a broader product or service and is caused by a social conformity process [2].

Consumer conformity classifies people into two groups, namely the conformity group and the non-conformity group. The conformity group is further classified into two groups, namely normative conformity and informational conformity. The Normative Conformity is a process of adjusting to other people's choices because of the desire to be liked by another person or group. Meanwhile, the Informational Conformity is the process of adjusting to other people's choices after receiving important information about these choices. In this case, normative conformity is often referred to as compliance and informational conformity is often referred to as acceptance. This definition explains that the conformity process is usually started by normative conformity, and then followed by informational conformity, continued by purchase intention.

The conformity theory introduced by Asch [14] stated that in the end people will adjust themselves to the choice of the majority of people even though they know that the majority is wrong. Therefore, conformity is an important aspect in marketing products and services, especially in an effort to increase purchase intention. Princes et al. [2] confirmed that customer conformity which is adhered to by social ties, social comparisons, image related concerns and strategic complement has been shown to have a significant effect on purchase intention.

Khandelwal et al. [4] analyzed consumer conformity separately according to its type, namely normative conformity and informational conformity. The proven normative conformity is influenced by involvement, motivation, and selfesteem while the proven informational conformity is influenced by trustworthiness and perceived expertise. Both normative and informational conformity are proven to have a positive effect on consumer attitude which also has a positive effect on purchase intention.

Consumer conformity refers to several groups of people. Park \& Yang [15] found that celebrity conformity has a positive effect on purchase intention. This shows that the level of popularity of a group of people can give birth to consumer conformity. The findings of previous studies prove that consumer conformity is formed from a social process and is proven to be an important marketing component and is able to increase purchase intention. If combined with the current situation, in the digital era, consumer conformity is becoming more and more widespread. Marketing using a consumer conformity strategy combined with digital technology will create a massive marketing concept that is not constrained by distance and time.

H1: Consumer conformity has a significant effect on purchase intention.

\subsection{Social ties}

Humans are social creatures, so they cannot be separated from social relationships. In the current era, social relations are not only in the real world but also occur in cyberspace. People started to have online friends and online communities, and they even started looking for life partners by using online platforms. This indicates that people are starting to believe, or even some people believe more information online than offline [16].

Online social network is a forum for sharing information related to a product or service. People began to believe that information on social media could be trusted and became one of the main references in the provision of products or services. Therefore, several platforms that provide products or services that do online marketing deliberately provide space for consumers to comment on their products. This is proven to be able to increase the image and market share more effectively. Therefore, online social ties cannot be ignored in the efforts of marketers to gain consumer trust.

Social ties are divided into two categories, namely strong ties and weak ties. Strong ties are relationships between individuals and their closest people, such as family or friends, while weak ties are relationships between individuals and acquaintances or other people who are not too close [1]. Everyone has strong and weak social ties and this relationship will greatly affect a person's life. Social ties are aspects that can lead or even change someone's opinion $[8,9]$ and it can be used to create consumer conformity [1].

Regarding the two categories of social ties, Wang et al. [17] found that strong ties in E-WOM were able to positively and significantly moderate the relationship between weak ties EWOM and purchase intention. Likewise, E-WOM's weak ties were able to positively moderate strong ties and purchase intention. Strong ties and weak ties have the engagement, because the decision taken by individual is influenced by many people, including the closest (strong ties), or others who are not that close, but are believed in assessing a product (weak ties). Therefore, in online social ties, when strong ties are good, it will increase the effect of weak ties and purchase intention. Likewise, if weak ties are good, it will moderate the strong ties with purchase intention.

Social interaction between people has a big role in determining purchase decisions, this relationship is known as consumer conformity [2]. Therefore, social ties are important aspect to increase consumer conformity [1, 2, 7-9] so as to increase purchase intention [1, 2, 18-21]. Social interactions that are carried out regularly will shape information sharing behavior which will shape the influence on purchase intention [18]. Choi [21] stated that social ties can increase consumer engagement and purchase intention.

H2: Social Ties has a significant effect on consumer conformity.

H3: Social Ties has a significant effect on purchase intention.

\subsection{E-WOM [Electronic Word of Mouth]}

Word of Mouth [WOM] is a non-commercial communication between several groups of consumers who provide feedback to each other regarding products and services to reduce the risk of incorrect selection of products and services [10]. Technological developments and the emergence of several online platforms that are widely used by 
the public have shifted WOM from direct communication to communication via online platforms such as Instagram, Facebook, Twitter and others. WOM activities that are carried out virtually on online platforms are called E-WOM [Electronic Word of Mouth].

E-WOM is defined as positive and negative statements based on experiences or facts that are shared with others via the internet and can have an influence on the assessment of a product or service [10]. E-WOM is also defined as a dynamic and continuous exchange of information related to experiences and facts related to products, brands, services or companies that can influence people through the internet media [11].

With the existence of E-WOM activities, the dissemination of information related to products and services is becoming faster and wider. E-WOM can be used by marketers to spread positive information related to the products or services they sell so that it can increase consumer conformity [10-13] and purchase intention [12, 13, 22-25].

This relationship can also occur because currently social media is one of the references for the community to determine purchasing decisions. Consumers will look for information related to brands, companies, products, and services on social media because they consider many other consumers to honestly share their purchasing experiences on social media [23]. This makes E-WOM a tool to increase the brand and market share of a company's products and services.

There are three motives for consumers in conducting EWOM, namely information validation, product evaluation, and purchase and post-purchase validation [10]. By utilizing E-WOM, the company is able to drive massive consumer opinion and increase marketing activities [11]. To support EWOM performance, there are three things needed, namely perceived persuasion, perceived informativeness, and source expertise [13]. E-WOM itself has three dimensions, which include quality, quantity, and credibility [12].

H4: E-WOM has a significant effect on consumer conformity.

H5: E-WOM has a significant effect on purchase intention.

\subsection{Purchase intention}

The customer journey from receiving information to purchasing consists of three overall stages, namely prepurchase, purchase, and post-purchase, as well as several other interactions between sellers and buyers [26]. The pre-purchase stage includes all features of customer interactions with the brand, category, and environment before the purchase occurs, and it involves behaviors such as need recognition, search, and consideration. The purchasing stage includes all customer interactions with the brand and its environment that occur during the purchase event and includes aspects such as ordering and payment. The post-purchase stage includes customer interactions with the brand and its environment that occur after purchase, and it contains behaviors such as use and consumption, post-purchase engagement, and service requests [26].

Purchase intention is the desire to buy a product or service in the future [23]. Intention to buy on social media has a concept that is broadly the same as the traditional way of buying. Social media users or online users have the intention to buy or purchase some products or services through social networking sites. Advances in technology encourage social media become the main reference in choosing a product and service, thus to increase purchase intention, social media is the right tool.

There are several key components in social media marketing, one of which is E-WOM that is useful for creating purchasing intention on social media. Social media users actively participate in various social networking sites or platforms to get the latest information about products or services. Peer-to-peer communication creates and shares information about products or services. Customer reviews and referrals direct customers to choose the appropriate product or service, from the many alternative products that are widely available. Social media users have the intention to buy digital and virtual goods through various social networking sites. To stay on social media, marketers need to be careful in delivering quality products or services to customers.

\section{RESEARCH METHOD}

The population in this study were consumers of the Shopee, Lazada, and Bukalapak platforms. From this population a sample of 200 respondents was taken. The data in this study were obtained by distributing questionnaires to all respondents. The questionnaire in this study includes the indicator of each variable, in which the indicator of consumer conformity is adopted from Wang et al. [17], social ties from Lee et al. [27], E-WOM from Aslam et al. [22], and purchase intention from Aslam et al. [22]. The results were analyzed using the Structural Equation Modeling [SEM] method using AMOS software. This study consists of two exogenous variables, namely social ties and EWOM and two endogenous variables, namely consumer conformity and purchase intention. Measurement of variables in this study uses the following indicators:

\section{Consumer Conformity [6]}

1. Recommendations from friends are important for me to purchase products and services online.

2. I will buy a product or service online if I have good reviews from other consumers.

3. I always ask others for consideration when buying products and services.

4. I like to find out what products and services people are interested in.

5. When I have limited information regarding a product and service, I ask my friends.

6. I often ask other people for recommendations when making a purchase.

7. I feel good when I buy products that others think are good.

\section{Social Ties [27]}

1. I have good relationships with friends both offline and online.

2. I have sufficient communication time with family and relatives.

3. I like chatting with other people.

\section{E-WOM [22]}

1. Reviews and recommendations from social media are my reference to buy a product or service.

2. Reviews and recommendations from social media can convince me.

3. Reviews on online platforms are quite objective.

4. The reviews on the online platform are quite valid and reliable. 


\section{Purchase Intention [22]}

1. After reading online reviews or comments on the internet, it makes me want to buy the product.

2. I will consider buying the product after I read online reviews or comments on the internet.

3. I intend to try the product or service discussed in the online review or comment on internet.

4. In the future, I intend to seek out the product or service discussed in the online review or comment on internet.

5. In the future, I intend to buy the product discussed in the online review or comment on internet.

\section{STATISTICAL ANALYSIS}

\subsection{Respondents' profile and characteristic}

Respondents' characteristic in this study is explained in several criteria, including gender, age, education, and income. The explanation of the respondents' characteristics is as follows in Table 1.

\subsection{Normality test and outlier}

The normality test is a test used to determine whether the data is normally distributed or not. In the data normality test, it is said to be normal if the multivariate $\mathrm{CR}$ value is in the range $+/-2.58$. The results of the normality test in this study are shown in Table 2.

The results of the normality test in Table 2 show that the multivariate $\mathrm{CR}$ value is -0.026 , which means that it is still in the $+/-2.58$ range, so the data in this study have been normally distributed.

Meanwhile, for the outlier test, it was carried out using the Mahalanobis Distance as a benchmark. Mahanalobis dsquared is the level of data deviation, which means that the data has a high outlier. The data with too high deviation or outlier must be dropped from the analysis. The data is said to contain no outliers if the value of the Mahalanobis distance does not exceed the chi square value. In this study, the chisquare value with a degree of freedom of 19 indicators at a level of $p<0.001$ is 36.19 . The outlier test results are as shown in Table 3.

The results of the analysis in Table 3 show that the highest Mahalanobis distance value in this study is 35.942 so that nothing exceeds 36.19 . Therefore, it can be concluded that the data in this study do not contain outliers.

\subsection{Confirmatory analysis}

Confirmatory analysis is used to test a concept built using several measurable indicators. In the confirmatory analysis, the first thing to look at is the loading factor value of each indicator. Loading factor is used to measure the validity of the construct, which according to Hair et al. [28] the minimum number of factor loading is $\geq 0.5$ or ideally $\geq 0.7$. If there is a value that is still below 0.5 it will be removed from the analysis. From the loading factor test, the results are found as shown in Table 4.

Table 1. Respondents' characteristic

\begin{tabular}{ccc}
\hline Gender & Frequency & Percentage \\
\hline Male & 95 & $47.50 \%$ \\
Female & 105 & $52.50 \%$ \\
Age & & \\
15-30 years old & 90 & $45 \%$ \\
31-40 years old & 62 & $31 \%$ \\
41-50 years old & 48 & $24 \%$ \\
Education & & \\
Elementary School & 0 & \\
Junior High School & 15 & $7.50 \%$ \\
Senior High School & 35 & $17.50 \%$ \\
Bachelor & 150 & $75 \%$ \\
Income & & \\
$<1.000 .000$ & 30 & $15 \%$ \\
1.000.000-5.000.000 & 111 & $55.50 \%$ \\
$>5.000 .000$ & 59 & $29.50 \%$ \\
Total Respondent & $\mathbf{2 0 0}$ & $\mathbf{1 0 0 \%}$ \\
\hline
\end{tabular}

Table 2. Normality test results

\begin{tabular}{ccccccc}
\hline Variable & min & max & skew & c.r. & kurtosis & c.r. \\
\hline CC7 & 2,000 & 5,000 &,- 668 & $-3,857$ &, 069 &, 199 \\
CC6 & 2,000 & 5,000 &,- 677 & $-3,907$ &, 345 &, 996 \\
CC5 & 2,000 & 5,000 &,- 876 & $-5,058$ &, 206 &, 596 \\
PI5 & 2,000 & 5,000 &,- 747 & $-4,315$ &, 287 &, 829 \\
PI4 & 2,000 & 5,000 & $-1,045$ & $-6,036$ &, 641 & 1,851 \\
EW4 & 2,000 & 5,000 &,- 494 & $-2,849$ &,- 400 & $-1,155$ \\
CC4 & 2,000 & 5,000 &,- 758 & $-4,376$ &,- 063 &,- 181 \\
PI3 & 2,000 & 5,000 &,- 781 & $-4,509$ &,- 006 &,- 017 \\
PI2 & 2,000 & 5,000 &,- 707 & $-4,083$ &, 367 & 1,059 \\
PI1 & 2,000 & 5,000 &,- 910 & $-5,251$ &, 117 &, 339 \\
EW1 & 2,000 & 5,000 &,- 790 & $-4,561$ &, 183 &, 529 \\
EW2 & 2,000 & 5,000 &,- 815 & $-4,706$ &, 220 &, 635 \\
EW3 & 2,000 & 5,000 &,- 725 & $-4,187$ &,- 075 &,- 216 \\
CC1 & 2,000 & 5,000 &,- 691 & $-3,990$ &, 076 &, 221 \\
CC2 & 2,000 & 5,000 &,- 802 & $-4,629$ &, 349 & 1,006 \\
CC3 & 2,000 & 5,000 &,- 566 & $-3,265$ &,- 144 &,- 415 \\
ST1 & 2,000 & 5,000 &,- 701 & $-4,050$ &,- 099 &,- 285 \\
ST2 & 2,000 & 5,000 &,- 768 & $-4,436$ &, 258 &, 745 \\
ST3 & 2,000 & 5,000 &,- 690 & $-3,984$ &, 119 &, 344 \\
Multivariate & & & & &,- 103 &,- 026 \\
\hline
\end{tabular}


Table 3. Outlier test result

\begin{tabular}{cccc}
\hline Observation number & Mahalanobis d-squared & p1 & p2 \\
\hline 155 & 35,942 &, 011 &, 363 \\
74 & 34,551 &, 016 &, 389 \\
102 & 33,701 &, 020 &, 368 \\
134 & 32,308 &, 029 &, 519 \\
69 & 30,867 &, 042 &, 733 \\
\hline
\end{tabular}

Table 4. Loading factors value

\begin{tabular}{cccc}
\hline & & & Estimate \\
\hline ST3 & $<---$ & Social_Ties &, 949 \\
ST2 & $<---$ & Social_Ties &, 941 \\
ST1 & $<---$ & Social_Ties &, 654 \\
CC3 & $<---$ & Consumer_Conformity &, 903 \\
CC2 & $<---$ & Consumer_Conformity &, 811 \\
CC1 & $<---$ & Consumer_Conformity &, 854 \\
EW3 & $<---$ & EWOM &, 745 \\
EW2 & $<---$ & EWOM &, 778 \\
EW1 & $<---$ & EWOM &, 764 \\
PI1 & $<---$ & Purchase_Intention &, 568 \\
PI2 & $<---$ & Purchase_Intention &, 475 \\
PI3 & $<---$ & Purchase_Intention &, 702 \\
CC4 & $<---$ & Consumer_Conformity &, 919 \\
EW4 & $<---$ & EWOM &, 688 \\
PI4 & $<---$ & Purchase_Intention &, 626 \\
oPI5 & $<---$ & Purchase_Intention &, 641 \\
CC5 & $<---$ & Consumer_Conformity &, 824 \\
CC6 & $<---$ & Consumer_Conformity &, 810 \\
CC7 & $<---$ & Consumer_Conformity &, 862 \\
\hline
\end{tabular}

From the results of the loading factor analysis in Table 4, there are no indicators with loading factor value that is below 0.5 , except for PI2. Thus, the PI2 indicator must be dropped from the study. After dropping the invalid indicators, it can be concluded that all indicators can explain the variables in this study.

Furthermore, the confirmatory model suitability test is tested using the Goodness of Fit Index. Hair et al. [28] divided the GOFI criteria [Goodness of Fit Index] into 3 types of criteria, namely absolute fit indices, incremental fit indices, and parsimony fit indices. Of the three types of GOFI, there are 25 criteria in total. However according to Hair et al. [28] in the SEM-Amos analysis it does not require that all criteria are met, 4 - 5 criteria alone are sufficient as long as there are criteria that represent the three types of GOFI criteria.

In this study, two criteria were taken from each type of GOFI, namely RMSEA and GFI representing absolute fit indices, CFI and TLI representing incremental fit indices, then PGFI and PNFI representing parsimony fit indices.

Table 5. Goodness of fit test results

\begin{tabular}{ccccc}
\hline Fit Index & $\begin{array}{c}\text { Goodness of } \\
\text { Fit }\end{array}$ & Criteria & $\begin{array}{c}\text { Cut-off } \\
\text { value }\end{array}$ & Details \\
\hline Absolute Fit & RMSEA & $\leq 0.08$ & 0,070 & Fit \\
Incremental & GFI & $\geq 0.90$ & 0,913 & Fit \\
Fit & TLI & $\geq 0.90$ & 0.933 & Fit \\
Parsimony & CFI & $\geq 0.90$ & 0.949 & Fit \\
Fit & PNFI & $\geq 0.60$ & 0.620 & Fit \\
\hline
\end{tabular}

Furthermore, a Goodness of Fit analysis is carried out. From the results of the GOF test, it was found that the Goodness of Fit value was still not fulfilled. Therefore, the model had to be modified so that the Goodness of Fit criteria can be met.
Furthermore, to improve the GOF, modifications were made with reference to the modification index. The results of Goodness of Fit after modification are fit as shown in Table 5.

\subsection{Reliability test}

The reliability of the construct is good if the value of the construct reliability is $>0.7$ and the variance extracted is $>0.5$. The value of construct reliability and variance extracted is obtained through the calculation with the formulation below:

$$
\begin{aligned}
C R & =\frac{\left(\sum \text { Standard Loading }\right)^{2}}{\left(\sum \text { Standard Loading }\right)^{2}+\sum e} \\
V E & =\frac{\sum \text { Standard Loading }{ }^{2}}{\sum \text { Standard Loading }}+\sum e
\end{aligned}
$$

The results of the reliability test in this study are as shown in Table 6:

Table 6. Reliability test results

\begin{tabular}{ccc}
\hline Variable & $\begin{array}{c}\text { CR [construct } \\
\text { reliability] }\end{array}$ & $\begin{array}{c}\text { VE [variance } \\
\text { extracted] }\end{array}$ \\
\hline Social Ties [ST] & 0.9 & 0.7 \\
Consumer & 0.95 & 0.7 \\
Conformity [CC] & 0.8 & 0.6 \\
EWOM & 0.7 & 0.5 \\
Purchase Intention & \\
[PI] & &
\end{tabular}

From Table 6, it can be seen that the construct reliability of all variables has shown the value of $\geq 0.7$. As for the variance extracted in this study, each variable also has a value above 0.5 . So it can be concluded that the data used for this study are declared reliable.

\subsection{Hypothesis test}

The next analysis is a full model Structural Equation Model [SEM] analysis to test the hypotheses developed in this study. The results of the regression weight test in this study are shown in Figure 1 and Table 7.

If the test results show the CR value is above 1.96 and the probability value $(\mathrm{P})$ is below 0.05 or $5 \%$, the proposed research hypothesis is accepted. From the table of hypothesis test results, the results of this study are as follows:

1. Consumer Conformity has a positive and significant effect on Purchase Intention. This is evidenced by the $\mathrm{CR}$ value that is more than 1.96 , namely 3.436 and the $\mathrm{P}$ value which is already below 0.05 , namely 0.000 .

2. Social Ties have a positive and significant effect on Consumer Conformity. This is evidenced by the CR value which is more than 1.96 , namely 2.677 and the $\mathrm{P}$ value which is already below 0.05 , namely 0.007 .

3. Social Ties has a positive and significant effect on Purchase Intention. This is evidenced by the CR value which is more than 1.96 , namely 2.573 and the $\mathrm{P}$ value which is already below 0.05 , namely 0.010 .

4. EWOM has a positive and significant effect on Consumer Conformity. This is evidenced by the CR value which is more than 1.96 which is 9.647 and the $\mathrm{P}$ value which is already below 0.05 , namely 0.000 . 
5. EWOM has a positive and significant effect on Purchase Intention. This is evidenced by the CR value which is more than 1.96 , namely 6.741 and the $\mathrm{P}$ value which is already below 0.05 , namely 0.000 .

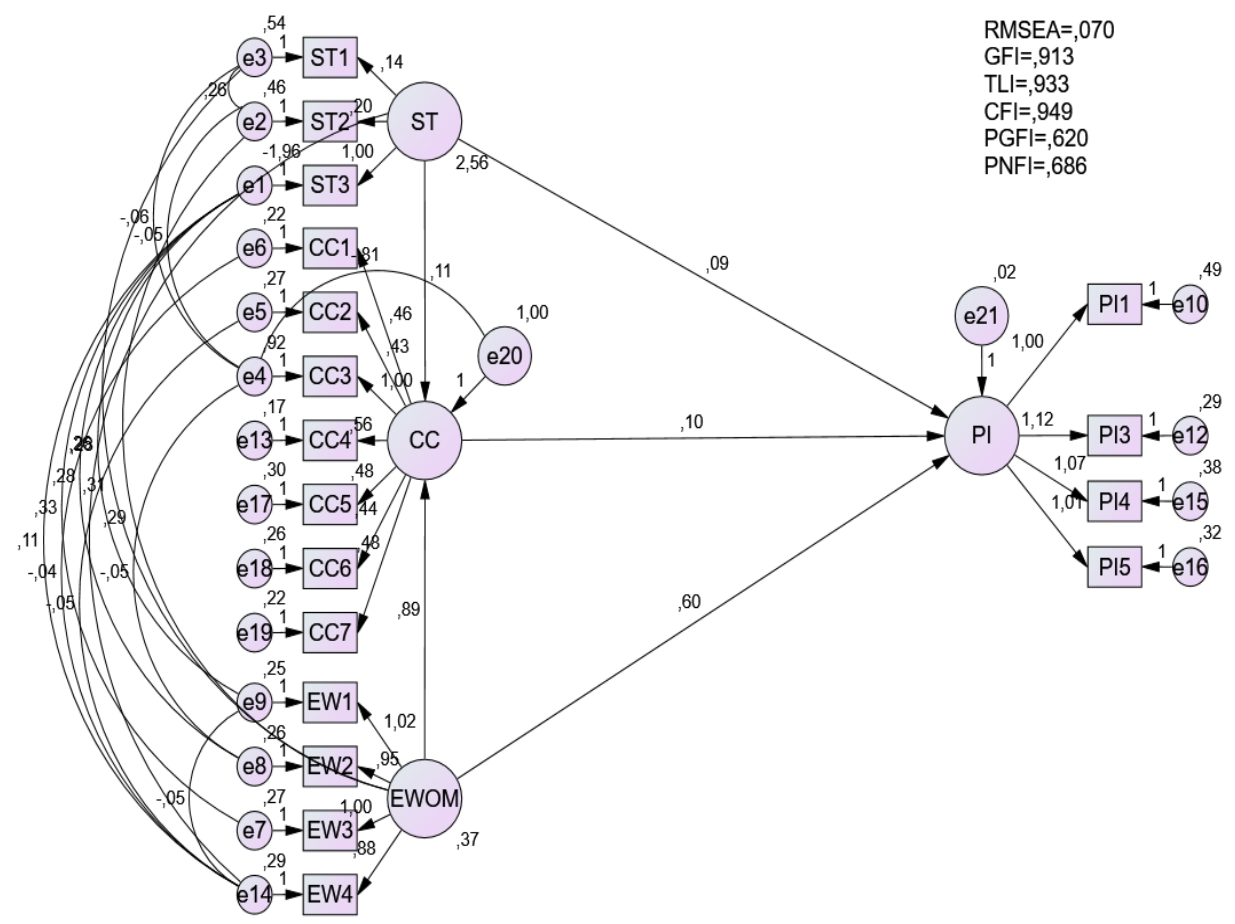

Figure 1. Path diagram of full model

Table 7. Results of regression weight of hypothesis test

\begin{tabular}{ccccccc}
\hline & & & Estimate & S.E. & C.R. & P \\
\hline Purchase_Intention & $<---$ & Consumer_Conformity &, 103 &, 030 & 3,436 & $* * *$ \\
Consumer_Conformity & $<---$ & Social_Ties &, 107 &, 040 & 2,677 &, 007 \\
Purchase_Intention & $<---$ & Social_Ties &, 088 &, 034 & 2,573 &, 010 \\
Consumer_Conformity & $<---$ & EWOM &, 894 &, 093 & 9,647 & $* * *$ \\
Purchase_Intention & $<---$ & EWOM &, 602 &, 089 & 6,741 & $* * *$ \\
\hline
\end{tabular}

\section{DISCUSSION AND IMPLICATION}

Digital marketing is a marketing technique that is considered the most efficient. Efforts to increase purchases through digital marketing are influenced by several variables. This study proves that consumer conformity, social ties, and EWOM are important variables in increasing purchase intention in digital marketing. This research analyzes the relationship between consumer conformity, social ties and EWOM in increasing purchase intention on digital marketing on three online shopping platforms, namely Shopee, Lazada and Bukalapak.

The results of this research indicate that consumer conformity has a significant effect on purchase intention. The significant relationship between consumer conformity and purchase intention is also confirmed by several previous studies such as [1-6]. Consumers from digital marketing are proven to have characters where they will tend to choose products or services that are chosen by many others. Consumer satisfaction will be fulfilled if they are able to buy products or services purchased by the majority of people, as this is a picture of consumer conformity that can increase purchase intention.

The results in this study emphasize that consumer conformity is an important variable in the success of digital marketing. Forming consumer conformity can be accelerated through two other variables, namely social ties and EWOM. This research also shows that social ties can increase consumer conformity. These results are supported by several previous studies such as $[1,2,7]$. Consumers who are close to family, relatives and friends have the potential to have a greater conformity, especially in digital marketing.

On the other hand, social ties have also been shown to be able to have a significant direct effect on purchase intention which has also been proven in several previous studies such [1, 2, 8, 17-21]. Orsingher and Cho [8] stated that the role of social ties in increasing consumer conformity and purchase intention arises because social ties can even lead to change someone's opinion regarding a product or service.

This research also shows that in increasing consumer conformity and purchase intention, there is a variable that is also important, namely EWOM. Previous research also supports that EWOM can significantly improve consumer conformity [10-13] and purchase intention [12-13, 22-25].

\section{CONCLUSION}

This research is carried out in the context of the application of digital marketing on the Shopee, Lazada, and Bukalapak 
platforms. It is found that social ties and EWOM can have a significant influence on consumer conformity and can also directly influence purchase intention. This research also highlights that consumer conformity has a significant effect on purchase intention in digital marketing.

\section{REFERENCES}

[1] Princes, E., Manurung, A.H. (2020). Taking advantage of social conformity in entrepreneurship. Journal of Management and Marketing Review, 5(1): 64-73. http://dx.doi.org/10.2139/ssrn.3551054

[2] Princes, E., Manurung, A.H., So, I.G., Abdinagoro, S.B. (2020). The next level of purchase intention. International Journal of Advance Science and Technology, 29(10): 441-448. Retrieved from http://sersc.org/journals/index.php/IJAST/article/view/1 4448.

[3] Chaouali, W., Yahia, I.B., Souiden, N. (2016). The interplay of counter-conformity motivation, social influence, and trust in customers' intention to adopt Internet banking services: The case of an emerging country. Journal of Retailing and Consumer Services, 28: 209-218

https://doi.org/10.1016/j.jretconser.2015.10.007

[4] Khandelwal, U., Yadav, S.K., Tripathi, V., Agrawal, V. (2018). E-Consumer conformity and its impact on consumer attitude. Journal of Asia Business Studies, 12(4): 455-468. https://doi.org/10.1108/JABS-09-20150161

[5] Song, W., Jin, X., Gao, J., Zhao, T. (2020). Will buying follow others ease their threat of death? An analysis of consumer data during the period of COVID-19 in China. International Journal of Environmental Research and Public Health, $17(15)$ : 3215. https://doi.org/10.3390/ijerph17093215

[6] Tsao, C.W., Hsieh, M.T., Shih, L., Lin, T. (2015). Compliance with eWOM: The influence of hotel reviews on booking intention from the perspective of consumer conformity. International Journal of Hospitality Management, 45: 99-111. https://doi.org/10.1016/j.ijhm.2015.01.008

[7] Tümen, S. (2017). Career choice and the strength of weak ties. Central Bank Review, 17(9): 91-97. https://doi.org/10.1016/j.cbrev.2017.08.002

[8] Orsingher., C., Wirtz, J., Cho, H. (2019). Engaging customers through online and offline referral reward programs. European Journal of Marketing, 53(9): 19621987. https://doi.org/10.1108/EJM-10-2017-0756

[9] Davoudi, A., Chatterjee, M. (2018). Social trust model for rating prediction in recommender systems: Effects of similarity, centrality, and social ties. Online Social Networks and Media, 7: 1-11. https://doi.org/10.1016/j.osnem.2018.05.001

[10] Ngarmwongnoi, C., Oliveira, J.S., AbedRabbo, M., Mousavi, S. (2020). The implications of eWOM adoption on the customer journey. Journal of Consumer Marketing, 37(7): 749-759. https://doi.org/10.1108/ JCM-10-20193450

[11] Ismagilova, E., Slade, E., Rana, N., Dwidedi, Y. (2019). The effect of electronic word of mouth communications on intention to buy: A meta-analysis. Information Systems Frontiers, 22(5): 1203-1226. https://doi.org/10.1007/s10796-019-09924-y

[12] Mehyar, H., Saeed, M., Al-Ja'afreh., Al-Adaileh. (2020). The impact of electronic word of mouth on consumers purchasing intention. Journal of Theoretical and Applied Information Technology, 98(02): 183-193.

[13] Tien, D.H., Rivas, A.A., Liao, Y.K. (2019). Examining the influence of customer-to-customer electronic wordof-mouth on purchase intention in social networking sites. Asia Pacific Management Review, 24(3): 238-249. https://doi.org/10. 1016/j.apmrv.2018.06.003

[14] Asch, S.E. (1956). Studies of independence and conformity: I. A minority of one against a unanimous majority. Psychological Monographs: General and Applied, 70(9): 1-70. https://doi.org/10.1037/h0093718

[15] Park, S.Y., Yang, Y. (2010). The effect of celebrity conformity on the purchase intention of celebrity sponsorship brand: The moderating effects of symbolic consumption and face-saving. Journal of Global Fashion Marketing: Bridging Fashion and Marketing, 1(4): 215229. https://doi.org/10.1080/20932685.2010.10593073

[16] You, L., Hon, L. (2019). How social ties contribute to collective actions on social media: A social capital approach. Public Relations Review, 45(4): 101771. https://doi.org/10.1016/j.pubrev.2019.04.005

[17] Wang, J., Wang, L., Wang, M. (2018). Understanding the effects of eWOM social ties on purchase intentions: A moderated mediation investigation. Electronic Commerce Research and Applications, 28: 54-62. https://doi.org/10.1016/j.elerap.2018.01.011

[18] Ghahtarani, A., Sheikhmohammady, M., Rostami, M. (2020). The impact of social capital and social interaction on customers' purchase intention, considering knowledge sharing in social commerce context. Journal of Innovation \& Knowledge, 5(3): 190-198. https://doi.org/10.1016/j.jik.2019.08.004

[19] Liang, Q., Liao, X., Shang, J. (2020). A multiple criteria approach integrating social ties to support purchase decision. Computers \& Industrial Engineering, 147(32): 106655. https://doi.org/10.1016/j.cie. 2020.106655

[20] Yang, R., Che, T. (2020). Do social ties matter for purchase frequency? The role of buyers' attitude towards social media marketing. Computers in Human Behavior, 110: 106376. https://doi.org/10.1016/j.chb.2020.106376

[21] Choi, Y. (2019). The study of antecedents of consumer engagement and purchase intention in social commerce. International Journal of Cyber Behavior, Psychology and Learning, $\quad 9(2)$ : $51-63$ https://doi.org/10.4018/IJCBPL.2019040104

[22] Aslam, W., Farhat, K., Arif, I. (2019). Role of electronic word of mouth on purchase intention. International Journal of Business Information Systems, 30(4): 411-426. https://doi.org/10.1504 /IJBIS.2019.099304

[23] Sulthana, A.N., Vasantha. (2019). Influence of electronic word of mouth eWOM on purchase intention. International Journal of Scientific \& Technology Research, 8(10): 1-5.

[24] Anastasiei, B., Chiosa, A.R. (2018). Antecedents of word-of-mouth communication and purchase intention on Facebook. Journal of Marketing and Consumer Behaviour in Emerging Markets, 2(8): 33-45. http://dx.doi.org/10.7172/2449-6634.jmcbem.2018.2.3

[25] Pektas, S.Y., Hassan, A. (2020). The effect of digital content marketing on tourists' purchase intention. Journal of Tourismology, 6(1): 79-98. 
https://doi.org/10.26650/jot.2020.6.1.0011

[26] Lemon, K.N., Verhoef, P.C. (2016). Understanding customer experience throughout the customer journey. Journal of Marketing, 80(6): 69-96. https://doi.org/10.1509/jm.15.0420

[27] Lee, J.H., Kim, J.H., Choi, J.Y. (2018). The adoption of virtual reality devices: The technology acceptance model integrating enjoyment, social interaction, and strength of the social ties. Telematics and Informatics, 39: 37-48. https://doi.org/10.1016/j.tele.2018.12.006

[28] Hair, J.F.Jr., Black, W.C., Babin, B.J., Anderson, R.E. (2010). Multivariate Data Analysis. $7^{\text {th }}$ Edition, Person Prentice Hall, Essex, UK. 